12. Rada AG. Spain's tougher line on smoking in public places spreads to other countries. BMJ 2011;342:d617.

13. Hajek $\mathbf{P}$, Stead LF, West $R$, et al. Relapse prevention interventions for smoking cessation. Cochrane Database Syst Rev 2005;(1):CD003999.

14. Richardson L, Hemsing N, Greaves L, et al. Preventing smoking in young people: a systematic review of the impact of access interventions. Int $J$ Environ Res Public Health 2009;6:1485-514.

15. Stead LF, Lancaster T. Interventions for preventing tobacco sales to minors. Cochrane Database Syst Rev 2005;(1):CD001497. [Update of Cochrane Database Syst Rev 2002;(1):CD001497]
16. Millett C, Lee J, Gibbins D, et al. Increasing the age for the legal purchase of tobacco in England: impacts on socioeconomic disparities in youth smoking. Thorax 2011;66:862-5.

17. Sowden A, Arblaster L, Stead L. Community interventions for preventing smoking in young people. Cochrane Database Syst Rev 2003;(1):CD001291. [Update of Cochrane Database Syst Rev 2000;(2): CD001291].

18. Brinn MP, Carson KV, Esterman AJ, et al. Mass media interventions for preventing smoking in young people. Cochrane Database Syst Rev 2010;(11):
CD001006. [Update of Cochrane Database Syst Rev 2000:(2):CD001006]

19. Hughes JR, Stead LF, Lancaster $T$, et al. Antidepressants for smoking cessation. Cochrane Database Syst Rev 2007;(1):CD000031. [Update of Cochrane Database Syst Rev 2004;(4): CD000031]

20. Stead LF, Perera R, Bullen C, et al. Nicotine replacement therapy for smoking cessation. Cochrane Database Syst Rev 2008;(1):CD000146.

21. Cahill K, Stead LF, Lancaster T, et al. Nicotine receptor partial agonists for smoking cessation. Cochrane Database Syst Rev 2007;(1):CD006103.

\title{
Protecting young people from smoking imagery in films: whose responsibility?
}

\section{$\checkmark$ Ailsa Lyons, John Britton \\ EDITOR'S \\ CHOICE}

Every day thousands of children try a cigarette for the first time, a seemingly innocuous step that for many leads to a lifelong and ultimately fatal addiction to smoking. Preventing this early experimentation is crucially important to preventing the huge toll of death and disability-particularly from respiratory diseases-that smoking causes. There is now increasing international evidence that exposure to smoking behaviour and other imagery in films is a major cause of smoking experimentation and uptake among children and young people. ${ }^{1-3}$ Three new studies in this issue of Thorax provide further evidence on this effect, this time in UK populations.

In a study of 15-year-old adolescents in the Avon birth cohort, Waylen et al demonstrate a direct relation between exposure to smoking in films and experimentation with smoking which remains significant even after exhaustive adjustment for potential confounders. Among Scottish adolescents exposed to smoking in films, Hunt et at ${ }^{5}$ report an exposurerelated increase in the odds of smoking that was enhanced by allowance for

UK Centre for Tobacco Control Studies, Division of Epidemiology and Public Health, The University of Nottingham, Nottingham, UK

Correspondence to Ailsa Lyons, UK Centre for Tobacco Control Studies, Division of Epidemiology and Public Health, The University of Nottingham, Clinical Sciences Building, City Hospital, Hucknall Road, Nottingham NG5 1PB, UK; mcxal4@nottingham.ac.uk 2002. repeated viewings. In a wider European study, Morgenstern et al demonstrate exposure-related increases in the odds of smoking among adolescents exposed to smoking in films in six countries, including the UK, demonstrating that this association applies across different cultural contexts and levels of implementation of other tobacco control policy. These new studies thus provide further and urgent evidence in support of calls-as yet unheeded-for a radical overhaul of film classification to protect all children and young people from this pervasive and highly damaging imagery. 2 3 $7-9$

The British Board of Film Classification (BBFC) is an independent organisation which, in return for fees paid by film makers, allocates all UK films intended for general release into one of five age classifications (table 1). ${ }^{10}$ The BBFC lists drug misuse and dangerous imitable behaviours as examples of harmful behaviour, and both $U$ and PG category guidance specifically proscribes 'potentially dangerous behaviour which young children are likely

to copy'. ${ }^{10}$ Smoking imagery is excluded from these categories, however, and acknowledged only, and if at all, in consumer advice printed on publicity materials and DVD cases or in extended classification information published on the BBFC website. ${ }^{11}$ As a result, as we have recently demonstrated, smoking and other forms of smoking imagery are extremely common in films classified as suitable for viewing by children and young people in the UK, and particularly so in films classified as suitable for viewing by children aged 12 and over. ${ }^{12}$

Our strong impression formed while carrying out that work is that, while some smoking in age-restricted films appears to be justified on artistic or factual grounds, the great majority is not. An example of the latter occurs in Avatar, the most popular film of all time and classified 12A in the UK, in which a lead adult character emerges from a sleeping pod in a science base on a distant planet over a century into the future to say, "Who's got my goddamn cigarette?" She then lights up and smokes throughout a conversation with other characters in a working environment in which smoking would be inconceivable even on 21st century Earth. The director of Avatar, James Cameron, justified the smoking on the grounds that 'from a character perspective, we were showing that Grace doesn't care about her human body, only her Avatar body'.13 Another and more egregious example is Remember Me, a 2010 'romantic drama set in New York City during the summer of

Table 1 British Board of Film Classification age-rated restriction categories for films viewed in UK cinema

\begin{tabular}{ll}
\hline Category & Description \\
\hline Universal (U) & Suitable for all audiences \\
Parent guidance (PG) & General viewing, but some scenes may be unsuitable for young children \\
$12 / 12 A^{*}$ & (12) Suitable for 12 years and older; (12A) under 12s must be accompanied by an adult \\
15 & Suitable for 15 years and over \\
18 & Suitable for 18 years and older
\end{tabular}

*12 and 12A rated films have been amalgamated since the $12 \mathrm{~A}$ film rating replaced the 12 rating for cinema film viewing in 
2001 where Tyler, a rebellious young man, meets Ally through a twist of fate'. ${ }^{14}$ According to extended classification information, the original version of this film would have been classified 15 but, at the request of the makers, was awarded a $12 \mathrm{~A}$ classification on condition of removal of two scenes-one referring to sodomy and the other considered to contain excessive violence. ${ }^{15}$ Tyler smokes repeatedly, and in one scene particularly ostentatiously, ${ }^{16}$ throughout the film.

After the publication of our study on UK film content, ${ }^{12}$ we wrote to the BBFC suggesting that current practice was failing to protect children from this particularly harmful imagery. The BBFC responded that their guidelines were 'proportionate; take due account of the available evidence of harm; and reflect the clear wishes of the public', citing data from a recent public consultation and pointing out that 'any film which could potentially cause harm through encouraging smoking through tobacco imagery would be awarded an appropriate, restrictive classification'. ${ }^{17}$ At a subsequent meeting, however, the senior policy advisor who wrote the letter to us was unable to give an example of a film for which this had occurred. He also advised us that any change to current practice would be likely to provoke powerful opposition from the film industry, and was therefore unlikely to occur in the absence of public complaint or a directive from the Department for Culture, Media and Sport (DCMS), the government department that sets the fees that the BBFC charges for its services. We requested a meeting with the DCMS to explore their position and were refused in a letter stating that " $\mathrm{DCMS}$ ] believe that current safeguards are already fit for purpose'. ${ }^{18}$

At our meeting at the BBFC we raised the examples of Avatar and Remember $M e$, and we note that the latest BBFC Annual Report, published in June 2011, refers in detail to the Remember $\mathrm{Me}$ classification process. ${ }^{19}$ The report cites Remember $M e$ as a good example of sexual content that crossed the line between implication and portrayal that results in a $12 \mathrm{~A}$ rather than PG classification. It also remarks on two important factors relating to the smoking content: first, that Tyler was 21 and hence less identifiable with 12 year olds than previous characters played by the same actor (in the Twilight films); and second, that his smoking is constantly criticised by other characters for its health risks ( $p$ 35). ${ }^{19}$ The inconsistency and inadequacy of BBFC classification stringency in relation to these different forms of content-in which the balance between sexual portrayal and implication is finely judged, on the one hand, to be too much for a PG classification and discreet editing of language and violent content are requested and made to avoid a 15 classification, on the other, while the sustained and highly damaging imagery of a powerfully addictive and hazardous drug use throughout the film is considered acceptable for 12-year-old children to watch-is clearly evident.

BBFC classifications are not legally binding in the UK and can be overruled by Local Authorities with whom ultimate responsibility for cinema licensing lies. ${ }^{20}$ In practice, however, this rarely happens and a recent high-profile campaign to encourage Liverpool City Council to impose stricter local classifications on films containing smoking failed. ${ }^{21}$ Protecting children from an exposure that is so potentially damaging is, however, a national governmental responsibility $^{22}$ and the solution to the problem is simple: for UK and indeed other film classification agencies to apply, a default 18 classification on all films containing smoking in the absence of powerful justification ${ }^{3}$ and irrespective of whether the smoking is judged by regulators to be promotional or glamorous or offset by comments from other characters. Film makers are acutely aware of classification criteria and, as the Remember $\mathrm{Me}$ example demonstrates, are prepared to manage film content carefully to achieve a desired age classification. If smoking content contributed to classification decisions to a similar extent to other harmful imitable behaviours, film makers wanting to reach young audiences would think twice about the necessity for smoking in films. James Cameron would have found an alternative and almost certainly more credible way to communicate his character's disdain for her body. The lead character in Remember $\mathrm{Me}$ would have portrayed his roguish but lovable rebelliousness without resorting to cigarettes.

This simple but radical change in the landscape of film classification needs political leadership to make it happen. Earlier in 2011 the UK government published a new Tobacco Control Plan for England $^{23}$ which recognised the importance of smoking in films as a driver of uptake among young people, but as a response proposed only to work with media regulators and the entertainment industry to 'consider what more can be done'. Our dealings with the BBFC and
DCMS indicate that neither organisation is likely to consider that any change is necessary. To our knowledge, no other country has imposed mandatory adult film classification on films that contain unjustifiable smoking imagery. While at an international level the WHO Framework Convention on Tobacco Control, an international tobacco control treaty, proscribes tobacco advertising, promotion or sponsorship, it does not clearly address the problem of behavioural imagery as opposed to brand imagery in film. Therefore, in the rest of the world as in the UK, smoking in films remains a major and persistent driver of smoking uptake among children and young people which the actions of irresponsible film makers, incompetent regulators and insouciant politicians are abjectly failing to control.

Funding $\mathrm{AL}$ is a PhD student funded by the UK Centre for Tobacco Control Studies which is a UK Clinical Research Collaboration (UKCRC) Centre of Public Health Research Excellence with funding from the British Heart Foundation, Cancer Research UK, the Economic and Social Research Council, the Medical Research Council and the Department of Health, under the auspices of the UKCRC.

\section{Competing interests None.}

Provenance and peer review Commissioned; internally peer reviewed.

Thorax 2011:66:844-846

doi:10.1136/thoraxjnl-2011-200789

\section{REFERENCES}

1. The National Cancer Institute. The Role of the Media in Promoting and Reducing Tobacco Use. Tobacco Control Monograph No. 19 US Department of Health and Human Services National Institutes of Health, 2008. Report No 07-6242.

2. Hastings G, Angus K. Forever Cool: the Influence of Smoking Imagery on Young People. BMA Board of Science, 2008.

3. World Health Organization. Smoke-free Movies from Evidence to Action. Geneva: World Health Organization, 2009

4. Waylen A, Leary SD, Ness AR, et al. Cross sectional association between smoking depictions in films and adolescent tobacco use nested in a British cohort study. Thorax 2011;66:856-61.

5. Hunt K, Henderson M, Wight D, et al. Exposure to smoking in films and own smoking amongst Scottish adolescents: a cross-sectional study. Thorax 2011:66:866-74.

6. Morgenstern M, Poelen E, Karlsdottir S, et al. Smoking in movies and adolescent smoking: crosscultural study in six European countries. Thorax 2011;66:875-83.

7. Chapman S. What should be done about smoking in movies? Tob Control 2008;17:363-7.

8. Australian Medical Association. Take Something Out of Kids' Movies. Medical News Today, 2008. http:// www.medicalnewstoday.com/articles/101011.php.

9. Millett C, Glantz SA. Assigning an '18' rating to movies with tobacco imagery is essential to reduce youth smoking. Thorax 2010;65:377-8. 
10. BBFC. British Board of Film Classification: the Guidelines. London: British Board of Film Classifications, 2009. http://www.bbfc.co.uk/classification/guidelines.

11. PBBFC. Parents BBFC. London, 2011. http://www. pbbfc.co.uk/.

12. Lyons A, McNeill A, Chen $Y$, et al. Tobacco and tobacco branding in films popular in the UK 1989-2008. Thorax 2010;65:417-22.

13. Cieply M. James Cameron Responds to Critics of Smoking in 'Avatar'. The New York Times, Arts Beat, 2010. http://artsbeat.blogs.nytimes.com/2010/01/03/ james-cameron-responds-to-critics-of-avatarsmoking-scene/.

14. IMDb. Remember Me. 2011. http://www.imdb.com/ title/tt1403981/.

15. BBFC. Remember Me [BBFC reference BFF265345]. London, 2011. http://www.bbfc.co.uk/website/
Classified.nst/0/1F4AC2EF985BAF01802576E700 51COBF?OpenDocument.

16. IMDb. Remember Me [Clip: You can't smoke in here]. Screenplay Inc, 2011. http://www.imdb.com/video/ screenplay/vi108070681/.

17. BBFC. Letter from Senior Policy Advisor at the BBFC 2010. (Received: 12/05/2010). http://www.ukctcs. org/ukctcs/research/featuredprojects/tobaccoinfilm/ index.aspx.

18. DCMS. Letter from the Minister for Culture, Communications and Creative Industries. 2010. (Received: 07/07/2010). http://www.ukctcs.org/ ukctcs/research/featuredprojects/tobaccoinfilm/index. aspx.

19. BBFC. BBFC Annual Report 2010. London: BBFC, 2011. http://www.bbfc.co.uk/download/annualreports/BBFC AnnualReport 2010.pdf.
20. Licensing Act 2003, (Chapter 17). London: Her Majesty's Stationary Office, 2003 http://www.legislation.gov.uk/ukpga/2003/17/ section/150.

21. Liverpool City Council. Minutes for Licensing and Gambling Committee meeting, Jan 16 2009, 2.00 PM. Liverpool: Licensing and Gambling Committee; 2009 http://openlylocal.com/documents/4326-Minutes-forLicensing-and-Gambling-Com.

22. UN. Convention on the Rights of the Child. Geneva, 1989. http://www.unhcr.org/refworld/pdfid/ 3ae6b38f0.pdf

23. Department of Health. Healthy Lives, Healthy People: A Tobacco Control Plan for England. London 2011. http://www.dh.gov.uk/prod consum dh/ groups/dh digitalassets/documents/digitalasset/ dh $124960 \overline{0}$.pdf.

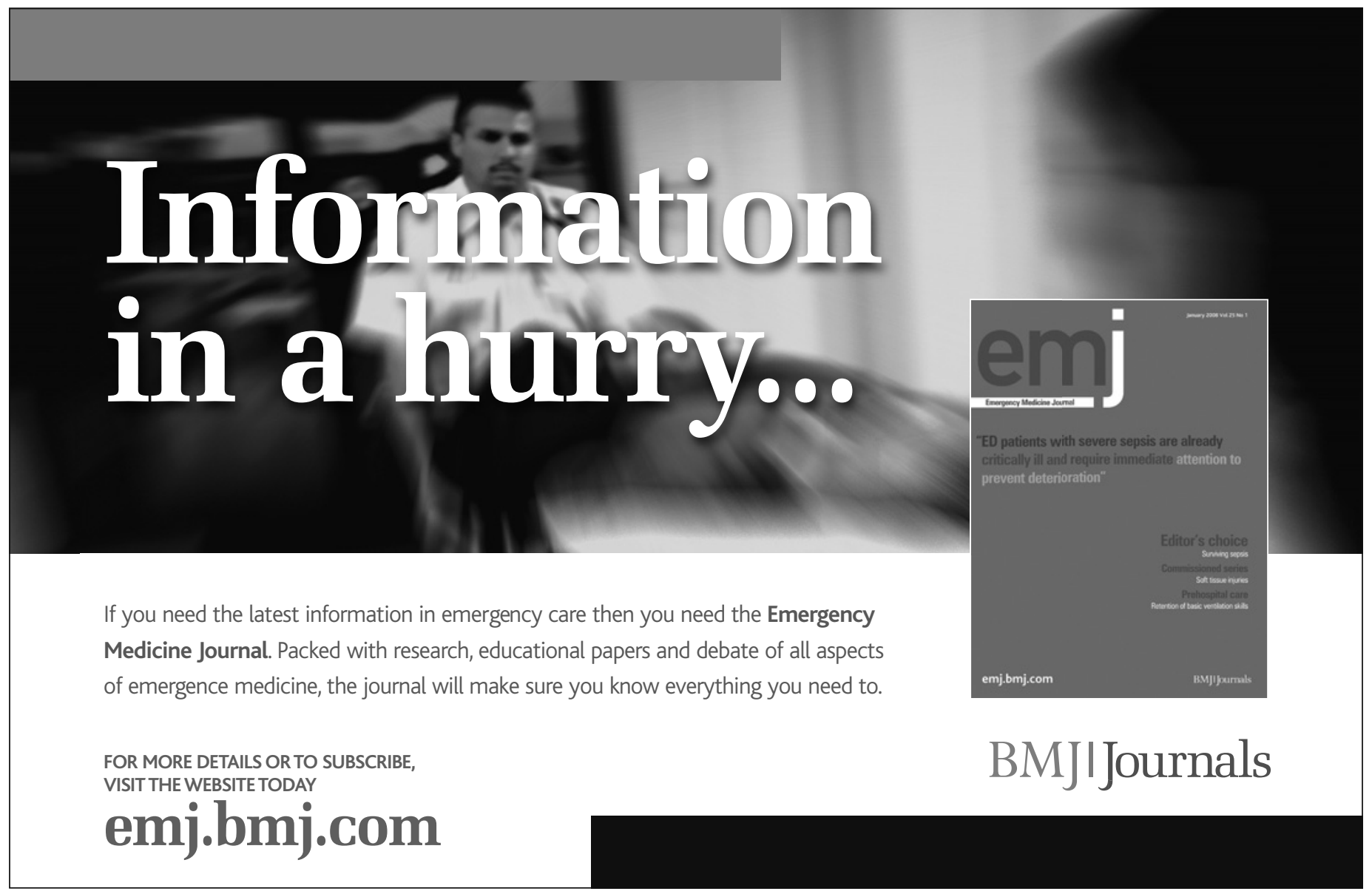

